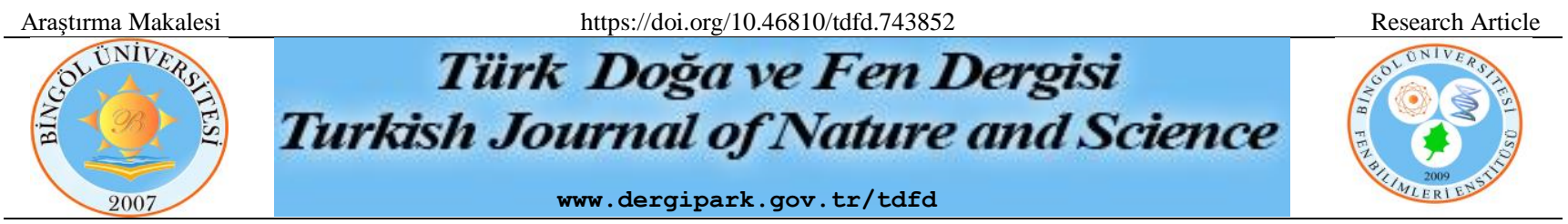

\title{
Turizm Yerleşim Alanlarında Peyzajda Kullanılan Bitkilerin Çeşitliliği: Edremit Körfezi
} (Balıkesir) Örneği

\author{
Rıdvan POLAT ${ }^{*}$, Selami SELVI' $\dot{\mathbf{I}}^{2}$ \\ ${ }^{1}$ Bingöl Üniversitesi, Ziraat Fakültesi, Peyzaj Mimarlığı Bölümü, Bingöl, Türkiye \\ ${ }^{2}$ Balıkesir Üniversitesi, Altınoluk Meslek Yüksekokulu, Bitkisel ve Hayvansal Üretim Bölümü, Balıkesir, Türkiye \\ Ridvan POLAT ORCID No: 0000-0003-0261-3671 \\ Selami SELVİ ORCID No: 0000-0002-9959-6945 \\ *Sorumlu yazar: rpolat@bingol.edu.tr
}

(Alınış: 28.05.2020, Kabul: 26.09.2020, Online Yayınlanma: 23.10.2020)

\begin{abstract}
Anahtar
Kelimeler

Edremit

Körfezi,

Peyzaj

düzenleme;

Peyzaj

bitkileri;

Balıkesir.

Öz: Edremit körfezi ülkemizin önemli turizm alanlarından biridir. $\mathrm{Bu}$ çalışmada, Edremit Körfezinde yer alan yerleşim alanları, turizm işletmeleri, site alanları ve konut çevrelerinde peyzaj amacı ile kullanılan ağaç/ağaççık, çalı ve otsu formundaki bitki türlerinin envanterinin çıkarılması amaçlanmıştır. Araştırma sonucunda 63 familyaya ait 126 cins ve 155 taksonun doğallaşmış ve egzotik peyzaj bitkisi olarak Edremit Körfezinde yetiştirildiği tespit edilmiştir. Familyaların \%68' i tek bir taksonla temsil edilmektedir. En fazla takson içeren familyalar; Fabaceae (13 takson), Rosaceae (12 takson) ve 8 taksonla Lamiaceae ve Pinaceae gelmektedir. En fazla taksona sahip cinsler; 4 taksonla Salvia olup bunu ve 3' er taksonla Abies, Acacia, Cupressus, Jasminum, Pinus ve Rosa takip etmektedir. Hayat formlarına göre peyzaj bitkilerinin \% 30' unu (46 takson) ağaç formu oluşturmaktadır. Bitkilerin genellikle süs-estetik, çit ve yer örtücü olarak kullanıldıkları tespit edilmiştir.
\end{abstract}

\section{Diversity of Plants Used in Landscape in Tourism Settlements: Edremit Bay (Balıkesir) Example}

Keywords Edremit bay, Landscape design, Landscape plants, Balıkesir.

\begin{abstract}
Edremit Bay is one of the important tourism areas of our country. In this study, it is aimed to take inventory of plant species in the form of trees, shrubs, bushes and herbaceous plants used for landscaping purposes in residential areas, tourism businesses, site areas and residential areas in Edremit Bay. As a result of the research, it was determined that 126 genera (155 taxa) belonging to 63 families were grown in Edremit Bay as a naturalized and exotic landscape plant. $68 \%$ of the families are represented by a one taxon. Families with the most taxa are Fabaceae (13 taxa), Rosaceae (12 taxa) and Lamiaceae and Pinaceae with 8 taxa. Genus with the most taxa is Salvia with 4 taxa and Abies, Acacia, Cupressus, Jasminum, Pinus and Rosa are followed by 3 taxa. According to life forms, $30 \%$ (46 taxa) of landscape plants are tree forms. It is determined that plants are generally used as ornamental-aesthetic, fence and groundcover in the area.
\end{abstract}

\section{GIIRIŞ}

Tarihin ilk çağlarından beri insanlar çevresinde yetişen bitkilerden başta besin kaynağı olmak üzere çok çeşitli amaçlarla yararlanmışlardır. Süs bitkileri şekil, form, renk ve estetik özellikleri ile öne çıkan otsu ve odunsu bitkiler olup, bu bitkiler çağlar boyu insanoğlunun acılarını ve sevinçlerini sembolize etmiş ve aynı zamanda teselli kaynağı olmuşlardır [1]. Peyzaj yapımında ana eleman olarak bitkiler statik olmayıp dinamik özellikler gösteren ve sürekli gelişen - değişen canlı varlıklardır. Fonksiyonel ve estetik yararları olan bitkiler yaşantımızda çok önemli bir yere sahiptirler [2]. Çevre düzenlemeleri içerisinde en önemli faktörü bitkiler teşkil etmektedir. Kent merkezlerindeki bitkiler kent ekosistemine nem kazandırma, hava kirliliğini önleme, enerji tasarrufu, fauna ve floraya yaşam ortamı hazırlama [3-4], gibi son derece önemli katkılarda bulunmaktadır. Bunun yanı sıra bitkilerin kent ekolojisine görsel ve işlevsel etkileri çok büyüktür [5]. Özellikle kent ortamlarında yeşil alan ve yapı dengesinin kurulması 
oldukça önemlidir. Türkiye'de nüfusun büyük bir oranı artık şehirlerde yaşamaya başlamış olup bu oran düzenli bir şekilde artmaya devam etmektedir. Bu artış şehirlerde plansız, düzensiz ve çarpık kentleşmeyi beraberinde getirmektedir [6].

Ülkemiz kentlerinde kişi başına düşen yeşil alan, gelişmiş ülkelerle kıyaslandığında oldukça düşük düzeyde kalmaktadır [6]. Son yıllarda kırsal alanlardan hızla uzaklaşıp kendi oluşturduğu yapay çevrede yaşamaya başlayan insanlar, doğaya olan özlemini onu korumaya ve doğa ile iç içe olabilecekleri mekânları tercih etme şeklinde göstermeye başlamışlardır. Böylece kentin açık yeşil alan sistemine katkıda bulunan ve rekreasyonel faaliyetlere olanak sağlayan kentsel yeşil alanların önemi de daha iyi fark edilmiştir [7]. Kentsel yeşil alanlar insanlara temiz hava, bol güneş ve serbest hareket etme ortamı sağlaması ile toplum için daha sağlıklı, dengeli, stres atıcı, yenileyici, ruhsal ve bedensel açıdan faydalı bir ortam oluşturmaktadır [8].

Türkiye'nin Ege denizindeki en kuzey körfezi ve aynı zamanda körfez kıyısını oluşturan Edremit Körfezi, Kazdağı ve Madra Dağları arasında yer alan; Ayvalık İlçesi'nin kuzeyinde Alibey Adası, Midilli Adası, Baba Burnu ve Akçay arasında uzanan üçgen şeklinde bir körfezdir [9-10]. Edremit Körfezi, doğal coğrafi özellikler bakımından insanların yerleşmesine, başta tarım ve turizm olmak üzere çeşitli ekonomik faaliyetleri bir arada yapabilmesine imkân veren önemli bir merkez konumundadır. $\mathrm{Bu}$ nedenle geçmişten günümüze kesintisiz yerleşim ve ekonomik etkinlik açısından önemli bir cazibe merkezi olmuştur. Son yıllarda da özellikle hızla artan turizm faaliyetleri sonucu körfez nüfusu 400 bine yaklaşmıştır [11].

Edremit körfezi yerleşim alanları (Küçükkuyu, Edremit, Burhaniye, Ayvalık, Gömeç) ve çevresinde yürütülen çalışmalarda park alanları, konut çevreleri ve site bahçelerinde yetiştirilen bitki türleri tespit edilip bu bitkilerin peyzajda kullanım özelikleri (estetik ve görsel) belirlenmiştir.

Ayrıca Edremit Körfezi gibi önemli bir turizm merkezinde gerçekleştirilen bu çalışmanın kentsel alanlarda yapılacak bitkilendirme - peyzaj tasarımlarında yol gösterici olması amaçlanmaktadır.

Kentsel açık-yeşil alanlarda kullanılan bitkisel çeşitlilik üzerine ülkemizde farklı kent merkezlerini kapsayan bazı çalışmalar yapılmıştır. Ülkemizde Trabzon, Rize, Artvin, Giresun, Ordu [12] ve Kahramanmaraş [13] gibi kent merkezlerinde benzer çalışmalar yürütülmüştür.

\section{MATERYAL VE METOT}

Çalışma alanında Küçükkuyu, Altınoluk, Güre, Akçay, Gömeç, Burhaniye, Ören, Pelitköy, Ayvalık, Sarımsaklı, Cunda, Küçükköy gibi önemli turizm merkezleri yer almaktadır (Şekil 1). Edremit Körfezinde karakteristik Akdeniz iklimi görülmektedir. Bu nedenle de Akdeniz iklimi ve bu iklim tipinin en karakteristik bitkilerinden biri olan zeytinin (Olea europaea L. subsp. europaea)
Türkiye'de yayılış gösterdiği alanlardandır. Thornthwaite iklim sinıflandırmasına göre, Edremit meteoroloji istasyonu verileri dikkate alındığında, çalışma alanı kurak ve az nemli, üçüncü dereceden mezotermal, kış mevsiminde çok kuvvetli su fazlası olan ve denizel şartlara yakın iklim tipine girmektedir [14]. Edremit Meteoroloji Genel Müdürlüğü'nden (MGM)' alınan verilere göre Edremit'te 11 yıllık sıcaklık ortalaması en yüksek Ağustos ayında $28,3{ }^{\circ} \mathrm{C}$ ve en düşük Ocak ayında $7.7{ }^{\circ} \mathrm{C}$ 'dir. 11 yıllık sıcaklık ortalaması ise $17.7^{\circ} \mathrm{C}$ 'dir. Yine MGM'den alınan verilere göre Edremit'te 11 yıllık ortalama yağış miktarı 64.2 mm'dir. Edremit'te aylık toplam yağışların yıl içindeki aylara dağılımı incelendiğinde Ocak ayından itibaren yağışın azaldığı, Eylül ayından itibaren yağışın arttığg gözlenmiştir. En fazla yağış Aralık ayında, en az yağış Temmuz ayında görülmektedir. En fazla yağışlı günler kış mevsiminde, en az yağış ise yaz mevsiminde görülmektedir [15].

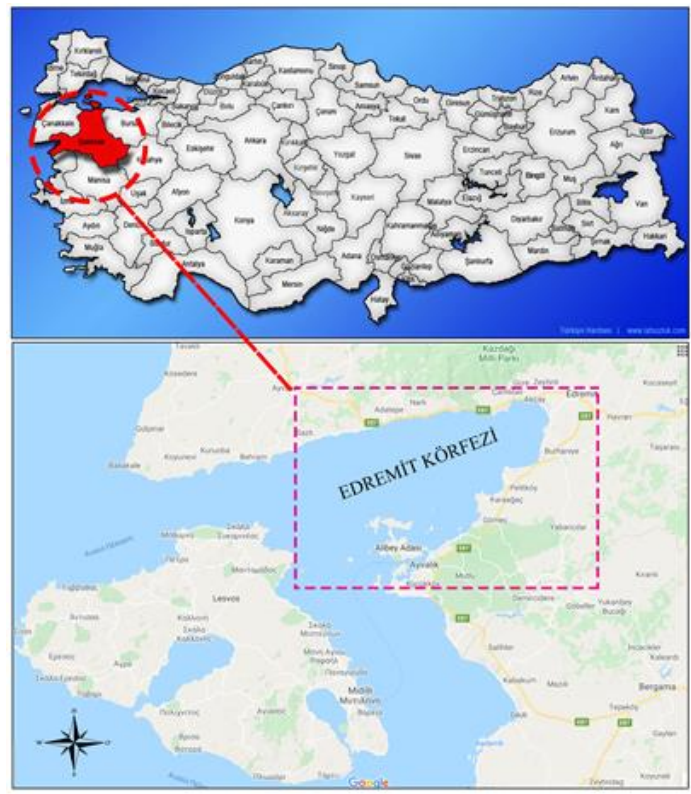

Şekil 1. Çalışma alanının genel görüntüsü

Çalışmada Körfez bölgesi belediyelerinden alınan kent merkezlerinin hazır haritaları ve uydu fotoğraflarından yararlanılmıştır. Çalışma alanında örnek bahçeler seçilirken ilk parametre olarak, yapılaşma yoğunluğu (kent dokusu) dikkate alınmıștır. Yapılaşma yoğunluğu kent merkezinde daha fazla olmakla birlikte kent merkezinden uzaklaştıkça çok sayıda yazlık konut ve site alanlarına rastlanılmaktadır. Arazi çalışmaları 2017-2019 yılları arasında ve bitki türlerinin kolay teşhis edilebilmesi açsından Nisan - Ekim ayları arasındaki dönemlerde yapılmıştır.

Alandaki bitkilerin teşhisi daha çok arazi çalışması esnasında yapılmıştır. Teşhis edilemeyen türlerden ise örnekler alınarak daha sonra teşhis edilmek üzere muhafaza edilmiştir. Bitkilerin teşhislerinde doğal ve egzotik bitkiler üzerine yapılmış çeşitli floristik eserlerden faydalanılmıştır [16-24]. Taksonların güncel bilimsel isimleri ve otör isimleri The Plant List'e [25] ve 
otör isimleri Brummit ve Powell (1992)'e göre düzenlenmiştir [26].

Genel analizler aşamasında bitki türlerinin peyzajda kullanım şekilleri (estetik ve görsellik, çit oluşturma, yüzey kaplama, gölgeleme, vurgu, doğallık vb.), çiçeklenme dönemleri, bulunma yoğunluğu, park ve konutlara göre dağılımı ve orijinleri belirlenmiştir. Çalışmalar esnasında tespit edilen bitki türleri arasından rastlanma oranı yüksek olan taksonların peyzajda kullanım şekilleri fotoğraflanmıştır.

\section{BULGULAR}

Araştırmalar sonucunda 63 familyaya ait 126 cins ve 155 taksonun peyzaj bitkisi olarak Edremit Körfezinde yetiştirildiği tespit edilmiştir (Tablo. 1). Familyaların $\% 68$ ' i tek bir taksonla temsil edilmektedir. En fazla takson içeren familyalar; Fabaceae (13 takson), Rosaceae (12 takson) ve 8 taksonla Lamiaceae ve Pinaceae gelmektedir (Şekil 2). En fazla taksona sahip cinsler ise; 4 taksonla Salvia olup bunu ve 3' er taksonla Abies, Acacia, Cupressus, Jasminum, Pinus ve Rosa takip etmektedir (Şekil 3).

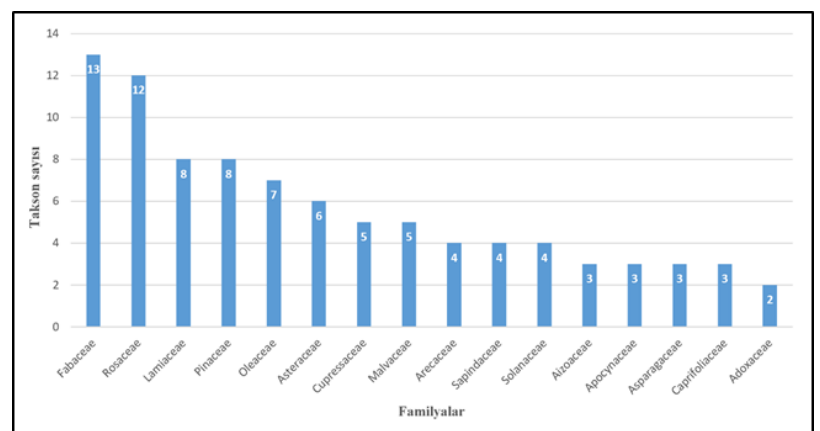

Şekil 2. En fazla taksona sahip familyalar

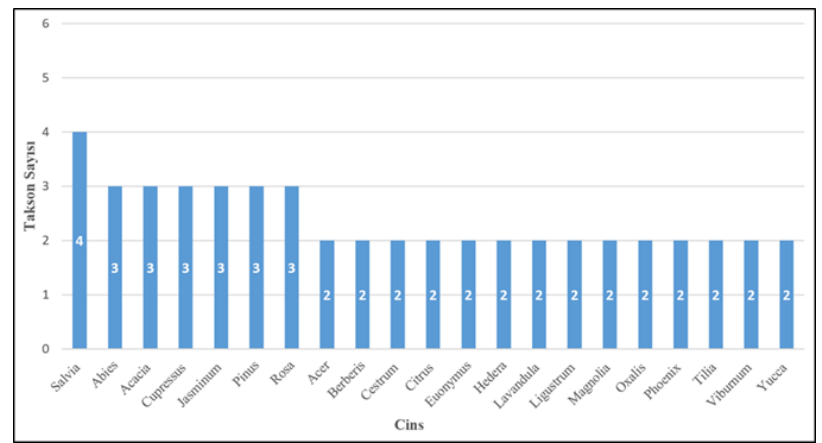

Şekil 3. En fazla takson içeren cinsler

Alanda tespit edilen bitkiler hayat formu üzerinden değerlendirildiğinde \% 30 ağaç, \% 28 çalı, \% 19 otsu, \% 14,2 çalı veya ağaçcık, \% 8,4' ü ise tırmanıcı formda oldukları belirlenmiștir (Şekil. 4). Ülkemizin önemli bir turizm merkezi olan alanda vurgu, renk ve form gibi estetik özellikleri ile öne çıkan türlerin yoğun olarak peyzaj çalışmalarında (Bougainvillea glabra Choisy., Citrus sinensis (L.) Osbeck., Cotoneaster horizontalis Decne., Euonymus japonicus Thunb., Nerium oleander L., Pyracantha coccinea M.Roem., Rosmarinus officinalis L., Syringa vulgaris L., Tagetes erecta L. Yucca gloriosa L.) kullanılmış olduğu belirlenmiştir.

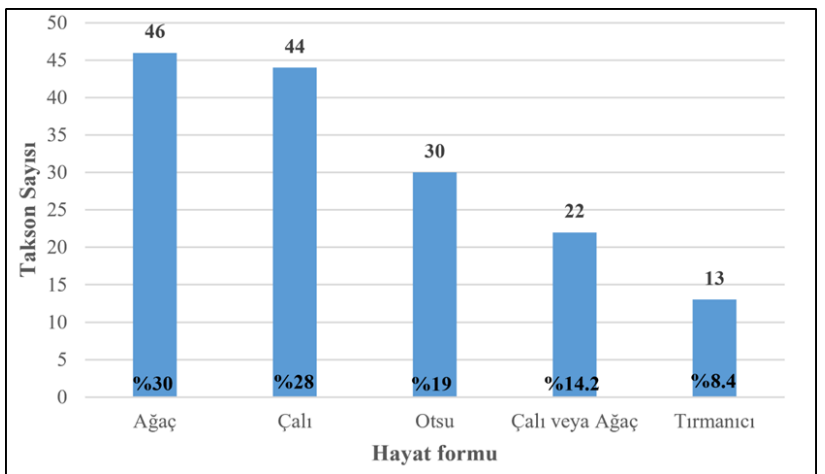

Şekil 4. Peyzaj bitkilerinin hayat formlarına göre dağılımı

Turizm alanlarında bitkilerin vurgu, renk ve form gibi estetik özellikleri göz önünde bulundurularak yapılan peyzaj kullanımlarının yoğun olduğu görülmüştür (Şekil 5).

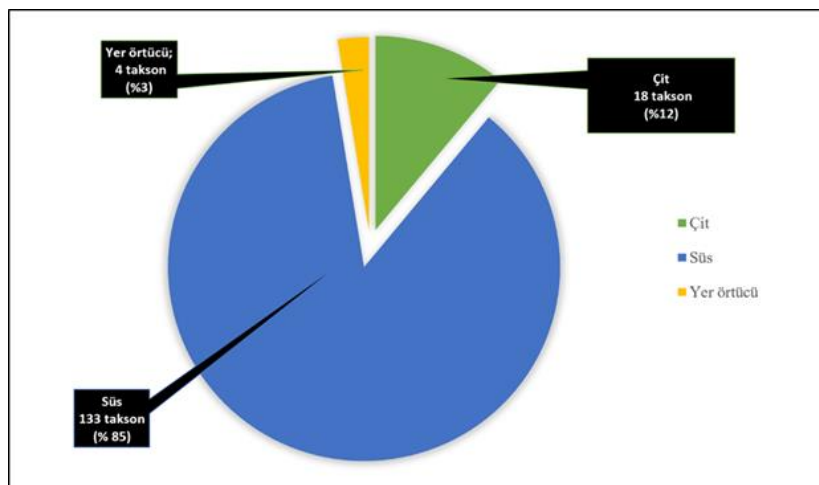

Şekil 5. Egzotik bitkilerin peyzajda kullanım amaçlarına göre dağılım grafiği

Ülkemizin önemli turizm alanlarından biri olan Edremit Körfezi'nde yapılan peyzaj çalışmalarında süs bitkilerinin yoğun olarak yetiştirildikleri görülmektedir (Şekil 6). Bununla beraber alandaki bitkilerin çit ve yer örtücü olarak kullanıldıkları tespit edilmiştir (Şekil 7). Bitki türlerinin orijinlerine bakıldığında tespit edilen bitkilerin ağırlıklı olarak egzotik bitki kategorisinde olduğu tespit edilmiştir. Yerleşim merkezlerinde yer alan konut ve site bahçelerinde daha fazla egzotik türlerin kullanılmış olduğu görülmüştür

Araştırma alanında ayrıca Salvia fruticosa Mill., Nerium oleander L., Laurus nobilis L., Rosa canina L., Cotoneaster horizontalis Decne. ve Hedera helix $\mathrm{L}$ vb. gibi bazı doğallaşmış bitki taksonları da yaygın olarak kullanılmaktadır. Araştırma alanında kaydedilen bitki türleri sınıflandırılırken herdem yeșil ve yaprağını döken türler olarak ta bir sınıflandırma yapılmıştır. Buna göre tespit edilen bitki taksonlarının 71'i herdem yeşil iken, 84 takson yaprak döken bitkiler kategorisindedir. Konut ve site alanlarında, herdem yeșil bitki türlerinin daha yoğun olarak tercih edildiği belirlenmiştir. 


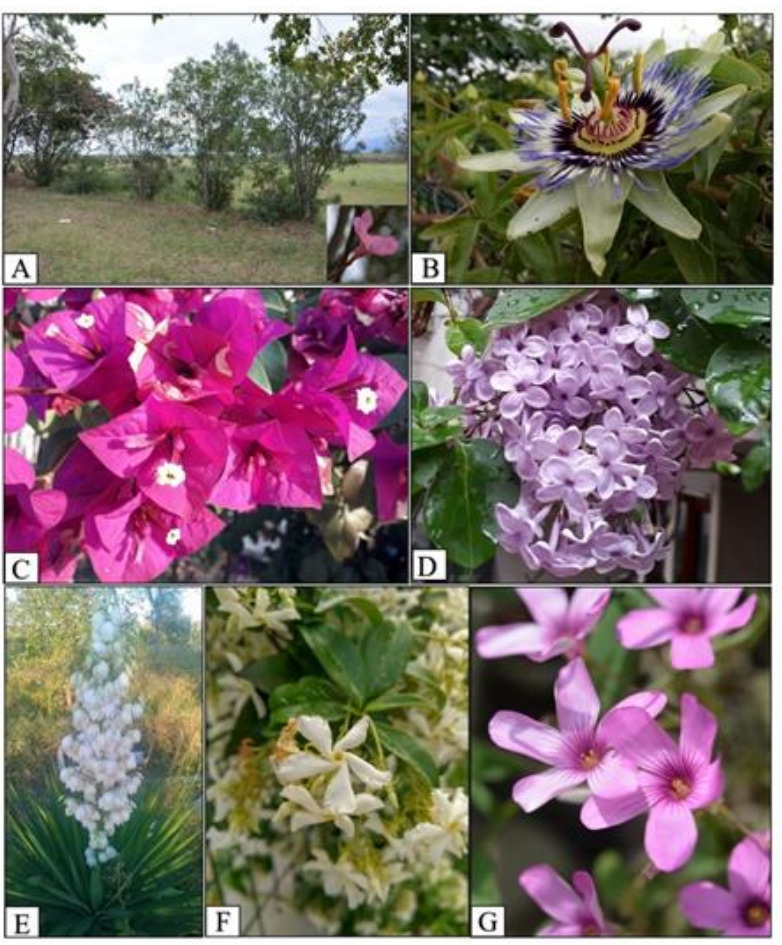

Şekil 6. Edremit Körfezi'nde süs olarak kullanımı yoğun olan türler: A) Nerium oleander B) Passiflora coerulea C) Bougainvillea glabra D) Syringa vulgaris E) Yucca glariosa F)Trachelospermum jasminioides $\mathrm{G})$ Oxalis articulata

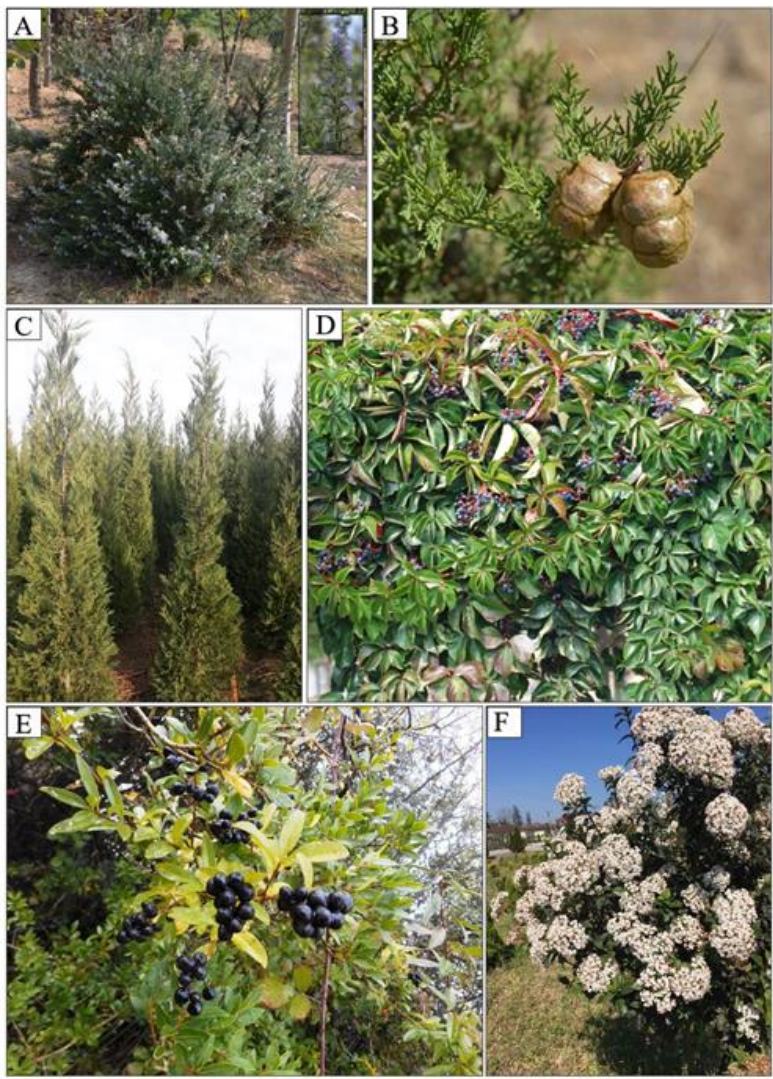

Şekil 7. Edremit Körfezi'nde çit olarak kullanımı yoğun olan türler: A) Rosmarinus officinalis B) Cupressus sempervirens C) Cupressus $x$ leylandii D) Parthenocissus quinquefolia E) Ligustrum vulgare F) Viburnum tinus

Araştırma alanında bulunan parklarda genellikle egzotik formlar ağırlıklı olmak üzere çok sayıda bitki çeşidi bulunmaktadır. Park ve bahçelerde yoğun olarak tercih edilen bitki taksonları Nerium oleander, Cotoneaster horizontalis, Mirabilis jalapa, Tagetes erecta, Rosa spp. Ligustrum spp. ve Yucca spp. şeklinde belirlenmiştir.

Turizm alanlarında yapılan peyzaj çalışmalarında ağırlıklı olarak egzotik bitkilerin kullanılması bazı alanlarda bölgenin doğal floral dokusuyla tezatlık oluşturmaktadır. Bazı alanlarda ise yapılan peyzaj çalışmalarında farklı türlerde çalı veya ağaç dikimi bitkisel tasarım kuralları göz ardı edilerek yapılmıştır.

\section{SONUC}

Edremit körfezi ülkemizin önemli turizm alanlarından biridir. Çalışma alanında yer alan turistlik otel, yazlık site ve konut çevrelerinde çok sayıda bitki peyzaj amacı ile kullanılmaktadır. Genel duruma bakıldığında egzotik türlerin bulunma yoğunluğu dikkat çekmektedir. Yerleşim merkezlerinden çevre alanlara doğru ilerledikçe yerleşim alanları çevresinde tercih edilen bitki türleri de kısmen değişkenlik göstermektedir. Konut kullanıcılarının sosyo-ekonomik durumları, gelenek ve kültürel alışkanlıkları bu konuda belirleyici konumdadır. Sosyo-ekonomik düzeyin yüksek olduğu alanlarda bitkisel çeşitlilik ve estetik zenginlik artarken, Sosyo- ekonomik düzeyin kısmen düşük olduğu alanlarda çeşitlilik azalırken peyzaj çalışmalarında daha çok bakım masrafları düşük olan herdem yeşil bitki formlarının çokça tercih edildiği görülmüştür. Daha önce yapılan birçok saha çalışmasına göre bitki çeşitliliği ve ekonomik refah arasında pozitif bir ilișki olduğunu ortaya koymuştur [27]. Tarihi kayıtlara göre, insan aktivitesinin olduğu alan içine giren bitki türleri kent alanlarında kendini çoğaltmaya, yayılmaya başlamaktadır. Kent flora ve vejetasyonundaki bu değişimler, doğal türlerin yok olması ve doğal olmayan türlerin doğallaşması eğilimi ile sonuçlanır [28]. Ficus carica, Cotinus coggygria, Salvia fruticosa, Nerium oleander, Laurus nobilis, Rosa canina, Cotoneaster horizontalis ve Hederahelix vb. çalışma alanında doğallaşmış bitki taksonlarına örnek olarak verilebilir.

Alanda mevsimsel olarak değişkenlik gösteren büyük bir nüfus yaşamaktadır. Çalışma alanında çok sayıda turistlik otel, yazlık site ve konut yer almaktadır. Alanda hızlı nüfus artışı ve yapılaşma yoğunluğu yeşil alanlar üzerinde büyük bir baskı oluşturmaktadır. Peyzaj çalışmalarının bölgenin doğal floral yapısı, bitkisel tasarım ve estetik kaygılar göz önünde bulundurularak yapılması, yerleşim alanlarının geleceği ve kentsel estetik için büyük bir önem taşımaktadır.

Tüm bu çalıșma ve tespitler göstermiștir ki; yerleșim alanlarında yer alan park alanları, turistik alanlar, konut ve sitelerde bitki tür çeşitliliği oldukça fazladır. Edremit Körfezi ve çevresinde elde edilen sonuçlara göre konut ve site bahçelerinde kullanılan bitki türleri peyzajda kullanım özelliklerine göre tercih edilmektedirler. Özellikle görsel ve estetik özellikler başta olmak üzere bitkilerin fonksiyonel ve ekolojik özellikleri bu konuda ön plana çıkmaktadır. Bitki tür çeşitliliğine dair yapılan araştırmaların kentsel alanlar ve kentsel ekosistemler üzerine yoğunlaşması gerekmektedir. Böylece her kentin 
kendine ait mevcut tür zenginliği ve bu bölgelere uyum sağlayabilen doğal türleri tespit edilebilir.

Turistik yerleşim alanlarında kullanılan bitkilerin peyzajda kullanım çeşitliliğinin belirlenmesi bu alanlarda yapılacak bitkilendirme çalışmalarına yön verebilir. Ayrıca yaratıcı tasarımlarla, mevcut doğal floral kaynaklardan daha iyi yararlanılması sağlanabilir.

\section{KAYNAKLAR}

[1] Kılıç Ö. Bingöl'de Süs Bitkisi Olarak Kullanılabilme Potansiyeli Olan Bazı Doğal Bitkiler. Peyzaj ve Süs Bitkiciliği Dergisi, 2018.

[2] Güçlü K. Erzurum'da kültürel çevrenin güzelleştirilmesinde kullanılabilecek süs ağaç ve ağaççıklarının yetiştirilmesi. Atatürk Üniversitesi Ziraat Fakültesi Dergisi 25, 461-468, 1994.

[3] Beckett K P, Freer-Smith P B, Taylor G. Urban woodlands: Their role in reducing the effects of particulate pollution. Environ. Pollut., 99, 347360, 1998

[4] Akbari R, Pomerantz M, Taha H. Cool surfaces and shade trees to reduce energy use and improve air quality in urban areas. Sol. Energy, 70(3), 295-310, 2001.

[5] Booth K N. Basic Elements of Landscape Architectural Design. Waveland Press, Illinois, 1990.

[6] Ekici B, Sarıbaş M. Bartın kenti peyzaj düzenlemelerinde kullanılan bitki materyalleri üzerine bir araștırma. ZKÜ Bartın Orman Fak. Dergisi, 8(9), 1-9, 2006.

[7] Konaklı N, Önder S. Arboretum kavramı ve Selçuk Üniversitesi, Kampus Alanı İçin Arboretum Oluşturulması Üzerine Bir Araştırma, Selçuk Üniversitesi, Ziraat Fakültesi Dergisi, 19: 16-29, 2005.

[8] Smardon, R C. Perception Aesthetics of the Urban Environment: Review of the Role of Vegetation, Landscape and Urban Planning, Elsevier Science Publication, B.V., Amsterdam, 105-120, 1990.

[9] Darkot B, Tuncel M. "Ege Bölgesi Coğrafyası", Edebiyat Fakültesi Matbaası. Devlet Su İşleri Genel Müdürlüğü (DSİ), 1995.

[10] Polat R, Selvi S. Edible macrofungi of Edremit Gulf (Balıkesir) in Turkey, African Journal of Biotechnology, 2011,10(51): 10431-10436.

[11] Yenigökçe Ö. Edremit Körfezi'nde yer alan ilçelerin nüfus değişimi. Yükseklisans Tezi. Çanakkale Onsekizmart Üniversitesi, Sosyal Bilimler Enstitüsü, Coğrafya A.B.D, 2019, Çanakkale

[12] Anşin R, Terzioğlu S. Doğu Karadeniz Bölgesinin Özellikle Trabzon Yöresinin Egzotik Ağaç ve Çalıları. Karadeniz Teknik Üniversitesi Genel Yayın No: 192, Orman Fakültesi Yayın No: 29, Tranbzon, s. 131, 1998.

[13] Dutkuner İ, Atken M. Kahramanmaraş’ta kent içi park ve ağaçlandırmalarda kullanılabilecek ağaç taksonları. Fen Müh., Derg, 3(2), 28-35, 2000.
[14] Tağıl Ş. Edremit Körfezı'nin Kuzey Sahil Bölgesinde Peyzaj Paterni ve Arazi Örtüsünün Zamansal ve Mekânsal Değişimi. Balıkesir Üniversitesi Sosyal Bilimler Enstitüsü Dergisi, 2014, 17(31):1-16.

[15] Anonim. T.C. Tarım ve Orman Bakanlığı Meteoroloji Genel Müdürlüğü 2. Bölge Müdürlüğü Balıkesir Edremit Meteoroloji İstasyonu Müdürlüğü, 2019.

[16] Gemici Y, Seçmen Ö, Acar İ, Görk G, Özel N. Kültürpark' in (İzmir) ağaç ve çalı türleri. İzmir Fuarcılık AŞ Yayınları, İzmir, 1992.

[17] Taverne, Y. Garden shrubs, flowers \& plants. Magna Books, England, 1995, 75p.

[18] Ceylan G. Diş mekân süs bitkileri ve peyzajda kullanımları. Flora Yayınları, İstanbul, 2004, $216 \mathrm{~s}$.

[19] Foulis, L., \& co-authors (Editors). Botanica, The illustrated A-Z of over 10,000 garden plants and how to cultivate them. h.f. Ullmann publishing GmbH, Germany, 2004, 1020p.

[20] Tuzlacı E. Türkiye' nin bahçe bitkileri ve kent çiçekleri. Türkiye İş bankası Kültür yayınları, 2010, No:11213, İstanbul.

[21] Yücel E. Çiçekler ve yerörtücüler. Türmatsan Organize Matbaacılık San. Ltd. Şti. Eskişehir, 2012a, 352s.

[22] Yücel E. Ağaçlar ve çalılar I. Türmatsan Organize Matbaacılık San. Ltd. Şti. Eskişehir, 2012b, 277s

[23] Akkemik Ü. (Editör). Türkiye'nin doğal-egzotik ağaç ve çalıları I, Gymnospermler-Angiospermler (A-G). Orman Genel Müdürlüğü Yayınları, Ankara, 2014a, 736s.

[24] Akkemik Ü. (Editör). Türkiye'nin doğal-egzotik ağaç ve çalıları II, Angiospermler (H-Z). Orman Genel Müdürlüğü Yayınları, Ankara, 2014b, 680s.

[25] Anonymous. The plant list. A working list of a plant species. [Online]. Available: May 2020, http://www.theplantlist.org.

[26] Brummitt, R. K, Powell C. E. Authors of Plant Names, Royal Botanic Gardens, Kew, 1992.

[27] Nelson A L, Schwirian K P, Schwirian P M. Social and economic distress in large cities, 1970- 1990: a test of the urban crisis thesis. Social Science Research, 1998, 27 , 410-431.

[28] Sukkop H (ed), Urban Ecology: Plants and Plant Communities in Urban Environments, SPB Publishing, The Hague, 2004, 45-74. 


\begin{tabular}{|c|c|c|c|c|c|c|c|c|}
\hline No & Bilimsel Adı & Familyası & Yöresel İsimleri & Kökeni & $\begin{array}{l}\text { Çiçeklenme } \\
\text { Dönemi }\end{array}$ & $\begin{array}{l}\text { Peyzajda Kullanım } \\
\text { Amacı (Süs/Estetik, Çit, } \\
\text { Yer örtücü, Koku, vb.??) }\end{array}$ & Formu & $\begin{array}{ll}\text { Herdem } & \text { Yeşil } \\
\text { durumu } & \end{array}$ \\
\hline 1 & Abelia grandifolia Villarreal & Caprifoliaceae & Abelya & Doğu Asya, Meksika & Mayıs-Kasım & Çit, Kokulu & Çalı & Herdem yeşil \\
\hline 2 & $\begin{array}{l}\text { Abies concolor (Gordon) Lindl. ex } \\
\text { Hildebr. }\end{array}$ & Pinaceae & Mavi göknar & Amerika, Meksika & - & Süs & Ağaç & Herdem yeşil \\
\hline 3 & Abies koreana E.H.Wilson & Pinaceae & Kore Göknarı & Güney Kore & - & Süs & Ağaç & Herdem yeşil \\
\hline 4 & Abies pinsapo Boiss. & Pinaceae & İspanyol Göknarı & Güney İspanya & - & Süs & Ağaç & Herdem yeşil \\
\hline 5 & Abutilon $\times$ hybridum Voss & Malvaceae & Çin lanterni & $\begin{array}{l}\text { Amerika, } \quad \text { Avustralya, } \\
\text { Afrika }\end{array}$ & Nisan-Eylül & Süs & Çalı & Değil \\
\hline 6 & Acacia dealbata Link & Fabaceae & Akasya & Tazmanya, Avustralya & Mart-Nisan & Süs & Ağaç & Herdem yeşil \\
\hline 7 & Acacia saligna (Labill.) Wendl. & Fabaceae & Akasya & Batı Avustralya & Mart-Haziran & Süs & Ağaç & Herdem yeşil \\
\hline 8 & Acacia retinodes Schltdl. & Fabaceae & İzmir Akasyası & Doğu Avustralya & Ağustos-Ekim & Süs & $\begin{array}{l}\text { Çalı ve ya } \\
\text { Ağaç }\end{array}$ & Herdem yeşil \\
\hline 9 & Acer negundo L. & Sapindaceae & İsfendan & Kuzey Amerika & - & Süs & Ağaç & Değil \\
\hline 10 & Acer palmatum Thunb. & Sapindaceae & Japon akçaağacı & Japon, Kore, Çin & - & Süs & Ağaç & Değil \\
\hline 11 & Aesculus hippocastanum L. & Sapindaceae & At kestanesi & Kuzey Amerika & Nisan-Mayıs & Süs & Ağaç & Değil \\
\hline 12 & $\begin{array}{l}\text { Agapanthus praecox } \\
\text { subsp. orientalis Leight. }\end{array} \quad$ Willd. & Amaryllidaceae & Agapanthus & Güney Afrika & Temmuz-Eylül & Süs & Otsu & Herdem yeşil \\
\hline 13 & Agave americana $\mathrm{L}$. & Asparagaceae & Agav & Kuzeydoğu Meksika & $10-20$ yilda birkez & Süs & Otsu & Herdem yeşil \\
\hline 14 & Ageratum houstonianum Mill. & Asteraceae & Vapur dumanı & $\begin{array}{l}\text { Orta Amerika, Batı } \\
\text { Hindistan }\end{array}$ & Haziran-Kasım & Süs & Otsu & Değil \\
\hline 15 & Ailanthus altissima (Mill.) Swingle & Simaroubaceae & Kokar ağaç & Çin & Mayıs-Haziran & Süs & Ağaç & Değil \\
\hline 16 & Albizia julibrissin Durazz. & Fabaceae & Gülbirişim & Japonya, Batı Asya & Mayıs-Ağustos & Süs & Ağaç & Değil \\
\hline 17 & Aloe arborescens Mill. & Xanthorrhoeaceae & Testere kaktüs & Güney Afrika & Temmuz-Eylül & Süs & Çalı & Herdem yeşil \\
\hline 18 & Berberis thunbergii DC. & Berberidaceae & $\begin{array}{l}\text { Berberis } \\
\text { tuzluğu }\end{array}$ & $\begin{array}{l}\text { Asya, Avrupa ve Kuzey } \\
\text { Amerika }\end{array}$ & Nisan - Mayıs & Süs & Çalı & Herdem yeşil \\
\hline 19 & Berberis aquifolium Pursh & Berberidaceae & Mahonya & Kuzey Amerika & Mart-Mayıs & Süs & Çalı & Herdem yeşil \\
\hline 20 & Bougainvillea glabra Choisy & Nyctaginaceae & Begonvil & Brazilya & Mart-Aralık & süs & Çalı & Herdem yeşil \\
\hline 21 & $\begin{array}{l}\text { Brachychiton populneus (Schott } \quad \& \\
\text { Endl.) R.Br. }\end{array}$ & Malvaceae & Yalancı kavak & $\begin{array}{l}\text { Avustralya ve Güneydoğu } \\
\text { Asya }\end{array}$ & Mayıs-Haziran & Süs & Ağaç & Değil \\
\hline 22 & $\begin{array}{l}\text { Brugmansia suaveolens Bercht. } \quad \& \\
\text { J.Presl }\end{array}$ & Solanaceae & Boru çiçeği & Güneydoğu Brezilya & Haziran-Ekim & Süs & $\begin{array}{l}\text { Çalı ve ya } \\
\text { Ağaç }\end{array}$ & Değil \\
\hline 23 & Buddleja davidii Franch. & Scrophulariaceae & Kelebek çalısı & Orta ve Batı Çin & Mayıs-Kasım & Süs & Çalı & Değil \\
\hline 24 & Buxus sempervirens $\mathrm{L}$. & Buxaceae & Şimşir & İngliiz adaları & Ocak-Nisan & Süs & Çalı & Herdem yeşil \\
\hline 25 & Caesalpinia gilliesii (Hook.) D.Dietr. & Fabaceae & Cennet çiçeği & Arjantin ve Uruguay & Haziran-Eylül & Süs & $\begin{array}{l}\text { Çalı ve ya } \\
\text { Ağaç }\end{array}$ & Değil \\
\hline 26 & $\begin{array}{l}\text { Callistemon linearis (Schrad.) Colv. } \\
\text { ex Sweet }\end{array}$ & Myrtaceae & Firça çalısı & Doğu Avustralya & Mayıs-Ağustos & Süs & Çalı & Herdem yeşil \\
\hline 27 & Campsis radicans (L.) Seem. & Bignoniaceae & Acem borusu & Güneydoğu Amerika & Mayıs-Ekim & Süs & Tirmanicı & Değil \\
\hline
\end{tabular}




\begin{tabular}{|c|c|c|c|c|c|c|c|c|}
\hline 28 & Canna indica $\mathrm{L}$. & Cannaceae & $\begin{array}{ll}\text { Tesbih } & \text { çiçeği, } \\
\text { Kanna }\end{array}$ & Amerika & Mayıs-Eylül & Süs & Otsu & Değil \\
\hline 29 & $\begin{array}{l}\text { Carpobrotus acinaciformis (L.) } \\
\text { L.Bolus }\end{array}$ & Aizoaceae & Makasotu & Güney Afrika & Mayıs-Haziran & Yer örtücü & Otsu & Değil \\
\hline 30 & Catalpa bignonioides Walter & Bignoniaceae & Katalpa & Güneydoğu Amerika & Mayıs-Temmuz & Süs & Ağaç & Değil \\
\hline 31 & Catharanthus roseus (L.) G.Don & Apocynaceae & Pervane çiçeği & Madagaskar & Mayıs-Kasım & Süs & Çalımsı & Herdem yeşil \\
\hline 32 & Cedrus libani A.Rich. & Pinaceae & Sedir & Lübnan & - & Süs & Ağaç & Herdem yeşil \\
\hline 33 & Celosia argentea $\mathrm{L}$. & Amaryllidaceae & Horoz ibiği & Asya, Afrika, Amerika & Mayıs-Eylül & Süs & Otsu & Değil \\
\hline 34 & Centranthus ruber (L.) DC. & Caprifoliaceae & Mahmuz çiçeği & $\begin{array}{l}\text { Avrupa, Kuzey Afrika, } \\
\text { Batı Asya }\end{array}$ & Nisan-Ağustos & Süs & Otsu & Değil \\
\hline 35 & Cercis siliquastrum $\mathrm{L}$. & Fabaceae & Erguvan & Güney ve Orta Avrupa & Nisan-Mayis & Süs & Çalı ve Ağaç & Değil \\
\hline 36 & $\begin{array}{l}\text { Cestrum elegans (Brongn. ex } \\
\text { Neumann) Schltdl. }\end{array}$ & Solanaceae & Sestrum & Meksika & Mayıs-Aralık & Süs & Çalı & Herdem yeşil \\
\hline 37 & Cestrum nocturnum $\mathrm{L}$. & Solanaceae & $\begin{array}{l}\text { Melisa, } \quad \text { Parfüm } \\
\text { çalısı }\end{array}$ & Meksika, Orta Amerika & Mayıs-Temmuz & Süs & Çalı & Herdem yeşil \\
\hline 38 & Chaenomeles speciosa (Sweet) Nakai & Rosaceae & Japon ayvası & Doğu Asya & Mart-Mayıs & Süs & Çalı & Değil \\
\hline 39 & $\begin{array}{l}\text { Chamaecyparis lawsoniana (A.Murra } \\
\text { y bis) Parl. }\end{array}$ & Cupressaceae & Yalancı Selvi & Kuzetbatı Amerika & - & Süs & Ağaç & Herdem yeşil \\
\hline 40 & Citrus limon (L.) Osbeck & Rutaceae & Limon & Güneydoğu Asya & Ocak-Aralık & Süs & Ağaç & Herdem yeşil \\
\hline 41 & Citrus sinensis (L.) Osbeck & Rutaceae & Portakal & Güneydoğu Asya & Kasım-Mayıs & Süs & Ağaç & Herdem yeşil \\
\hline 42 & Clerodendrum bungei Steud. & Lamiaceae & Klerodendrum & Çin & Temmuz-Eylül & Süs & Çalı & Değil \\
\hline 43 & Cosmos sulphureus Cav. & Asteraceae & Kozmoz & $\begin{array}{l}\text { Kuzey, Orta ve Güney } \\
\text { Amerika }\end{array}$ & Haziran-Eylül & Süs & Otsu & Değil \\
\hline 44 & Cotinus coggygria Scop. & Anacardiaceae & Duman ağacı & Asya, Avrupa & Mayıs-Temmuz & Süs & $\begin{array}{l}\text { Çalı veya } \\
\text { Ağą̧ }\end{array}$ & Değil \\
\hline 45 & Cotoneaster horizontalis Decne. & Rosaceae & Dağ muşmulası & $\begin{array}{l}\text { Avrupa, Güney Afrika ve } \\
\text { Asya }\end{array}$ & Nisan-Mayis & Çit & Çalı & Herdem yeşil \\
\hline 46 & Cupressus sempervirens L. & Cupressaceae & Servi & Doğu Akdeniz, Kuzey İran & - & Çit & Ağaç & Herdem yeşil \\
\hline 47 & $\begin{array}{l}\text { Cupressus } \times \text { leylandii A.B.Jacks. \& } \\
\text { Dallim. }\end{array}$ & Cupressaceae & Alaca melez servi & Kuzey İrlanda & - & Çit & Ağaç & Herdem yeşil \\
\hline 48 & Cupressus arizonica Greene & Cupressaceae & Amerikan servisi & Amerika & - & Çit & Ağaç & Herdem yeşil \\
\hline 49 & Cycas revoluta Thunb. & Cycadecae & $\begin{array}{l}\text { Sikas, } \\
\text { palmiye }\end{array}$ & Güney Japonya & - & Süs & Ağaç & Herdem yeşil \\
\hline 50 & Cyperus alternifolius $\mathrm{L}$. & Cyperaceae & Japon şemşiyesi & Doğu Afrika & - & Çit & Otsu & Herdem yeşil \\
\hline 51 & Dahlia pinnata Cav. & Asteraceae & Yildiz & Meksika, Orta Amerika & Haziran-Kasım & süs & Otsu & Değil \\
\hline 52 & Dianthus chinensis L. & Caryophyllaceae & Çin karanfili & Çin & Mayıs-Temmuz & Süs & Otsu & Değil \\
\hline 53 & $\begin{array}{l}\text { Drosanthemum hispidum (L.) } \\
\text { Schwantes }\end{array}$ & Aizoaceae & Tüylü halı çiçeği & Güney Afrika & Nisan-Temmuz & Yer örtücü & Otsu & Değil \\
\hline 54 & Duranta erecta $\mathrm{L}$. & Verbenaceae & Duranta, mavisalkım & Güney Amerika & Temmuz-Eylül & Süs & Çalı & Değil \\
\hline 55 & Elaeagnus angustifolia $\mathrm{L}$. & Eleagnaceae & İ̆ğe & Asya & Nisan-Haziran & Süs & $\begin{array}{l}\text { Çalı veya } \\
\text { Ağaç }\end{array}$ & Değil \\
\hline 56 & Eriobotrya japonica (Thunb.) Lindl. & Rosaceae & Yeni dünya & $\begin{array}{l}\text { Doğu Asya ( Çin, Japonya, } \\
\text { Tayvand) }\end{array}$ & Ekim-Ocak & Süs & $\begin{array}{ll}\text { Çalı } & \text { veya } \\
\text { Ağaç } & \\
\end{array}$ & Herdem yeşil \\
\hline
\end{tabular}




\begin{tabular}{|c|c|c|c|c|c|c|c|c|}
\hline 57 & Erysimum $\times$ cheiri $(\mathrm{L}$. $)$ Crantz & Brassicaceae & Şebboy & Güney Avrupa & Mart-Ağustos & Süs & Otsu & Değil \\
\hline 58 & Eucalyptus camaldulensis Dehnh. & Myrtaceae & $\begin{array}{l}\text { Sitma ağac1, } \\
\text { Okaliptus }\end{array}$ & Avustralya & Nisan-Haziran & Süs & Ağaç & Herdem yeşil \\
\hline 59 & $\begin{array}{l}\text { Euonymus fortunei (Turcz.) Hand.- } \\
\text { Mazz. }\end{array}$ & Celastraceae & Sürünücü taflan & Çin & Nisan-Haziran & Çit & Tirmanıcı & Herdem yeşil \\
\hline 60 & Euonymus japonicus Thunb. & Celastraceae & $\begin{array}{l}\text { Japon papaz külahı, } \\
\text { taflan }\end{array}$ & Japonya & Mayıs-Ağustos & Çit & Çalı & Herdem yeşil \\
\hline 61 & Euphorbia ingens E.Mey. ex Boiss. & Euphorbiaceae & Ağaç kaktüs & Güney Afrika & Şubat-Nisan & Süs & $\begin{array}{l}\text { Otsu } \\
\text { (sukkulent) }\end{array}$ & Değil \\
\hline 62 & Ficus carica $\mathrm{L}$. & Moraceae & İncir & Türkiye, Batı Asya & - & Süs, Gıda & $\begin{array}{l}\text { Çalı veya } \\
\text { Ağaç }\end{array}$ & Değil \\
\hline 63 & Forsythia $\times$ intermedia Zabel & Oleaceae & Altınçanak, Altınçan & Kuzey İrlanda & Mart-Mayıs & Süs & Çalı & Değil \\
\hline 64 & Gaura lindheimeri Engelm. \& A.Gray & Onagraceae & Gaura & Amerika, Meksika & Mayıs-Haziran & Süs & Çalı & Değil \\
\hline 65 & Gazania rigens (L.) Gaertn. & Asteraceae & Gazanya & Güney Afrika & Nisan-Kasım & Süs & Otsu & Değil \\
\hline 66 & Ginkgo biloba $\mathrm{L}$. & Ginkgoaceae & Ginko, Japon eriği & Çin & - & Süs & Ağaç & Değil \\
\hline 67 & Gleditschia triacanthos $\mathrm{L}$. & Fabaceae & $\begin{array}{l}\text { Glediçya, Yalancı } \\
\text { keçiboynuzu }\end{array}$ & Orta ve Doğu Amerika & Nisan-Haziran & Süs & Ağaç & Değil \\
\hline 68 & Grevillea rosmarinifolia A.Cunn. & Proteaceae & $\begin{array}{l}\text { Çalı grevillea, firça } \\
\text { çalısı }\end{array}$ & Güneydoğu Avustralya & Ağustos-Eylül & Süs & Çalı & Herdem yeşil \\
\hline 69 & Hedera helix $\mathrm{L}$. & Araliaceae & Duvar sarmaşı̆̆ı & Avrupa, Batı Asya & - & Süs & Tirmanıcı & Herdem yeşil \\
\hline 70 & Hedera colchica (K.Koch) K.Koch & Araliaceae & Duvar sarmaşı̆̆ 1 & Orta Doğu & - & süs & Tirmanıcı & Herdem yeşil \\
\hline 71 & Hibiscus mutabilis $\mathrm{L}$. & Malvaceae & Çin gülü, Japon gülü & Çin & Haziran-Aralık & Süs & $\begin{array}{l}\text { Çalı veya } \\
\text { Ağaç }\end{array}$ & Değil \\
\hline 72 & $\begin{array}{l}\text { Hydrangea macrophylla (Thunb.) } \\
\text { Ser. }\end{array}$ & Hydrangeaceae & Ortanca ççieği & Japonya & Mayıs-Kasım & Süs & Çalı & Değil \\
\hline 73 & Ilex aquifolium $\mathrm{L}$. & Aquifoliaceae & Çobanpüskülü & $\begin{array}{l}\text { Avrupa, Kuzey Afrika, } \\
\text { Batı Asya }\end{array}$ & Mayıs-Haziran & Süs & $\begin{array}{ll}\text { Çalı } & \text { veya } \\
\text { Ağaç } & \end{array}$ & Herdem yeşil \\
\hline 74 & Impatiens balsamina $\mathrm{L}$. & Balsaminaceae & $\begin{array}{l}\text { Camgüzel, } \\
\text { gelinmumu }\end{array}$ & Hindistan, Günay Asya & Hazirn-Eylül & Süs & Otsu & Değil \\
\hline 75 & Ipomoea quamoclit $\mathrm{L}$. & Convolvulaceae & Yıldız çadırı & Kuzey ve Doğu Avustralya & Haziran-Ekim & Süs & Otsu & Değil \\
\hline 76 & Jasminum polyanthum Franch. & Oleaceae & $\begin{array}{l}\text { Kokulu yasemin, } \\
\text { Yasemin }\end{array}$ & Çin & Şubat-Ağustos & Süs & Tirmanici & Herdem yeşil \\
\hline 77 & Jasminum mesnyi Hance & Oleaceae & Yasemin & Çin & Mart-Haziran & Süs & Çalı & Herdem yeşil \\
\hline 78 & Jasminum officinale L. & Oleaceae & $\begin{array}{l}\text { Kokulu yasemin, } \\
\text { Yasemin }\end{array}$ & Çin & Mayıs-Kasım & Süs & Tirmanıcı & Herdem yeşil \\
\hline 79 & Kerria japonica (L.) DC. & Rosaceae & Kanarya gülü, Kerya & Çin, Japonya & Mart-Ağustos & Süs & Çalı & Değil \\
\hline 80 & Koelreuteria paniculata Laxm. & Sapindaceae & Güveyfeneri & Çin, Kore & Haziran-Ağustos & Süs & Ağaç & Değil \\
\hline 81 & Lablab purpureus (L.) Sweet & Fabaceae & Selluka & Tropikal Afrika & Haziran-Ocak & Süs & Otsu & Değil \\
\hline 82 & Laburnum anagyroides Medik. & Fabaceae & Sarısalkım & Orta ve Güney Avrupa & Nisan-Mayıs & Süs & $\begin{array}{ll}\text { Çalı } & \text { veya } \\
\text { Ağaç } & \end{array}$ & Değil \\
\hline 83 & Lagerstroemia indica $\mathrm{L}$. & Lythraceae & Oya çiçeği & Çin & Mayı-Ekim & Süs & $\begin{array}{l}\text { Çalı } \\
\text { Ağaç }\end{array}$ & Değil \\
\hline 84 & Lantana camara $\mathrm{L}$. & Verbenaceae & Mine çiçeği & Güney Afrika & Mayıs-Aralık & Süs & Çalı & Herdem yeşil \\
\hline 85 & Laurus nobilis L. & Lauraceae & Defne & Kuzey Afrika, Batı Asya, & Mart-Mayıs & Süs & veya & Herdem yeşil \\
\hline
\end{tabular}




\begin{tabular}{|c|c|c|c|c|c|c|c|c|}
\hline & & & & Güney Avrupa & & & Ağaç & \\
\hline 86 & Lavandula angustifolia Mill. & Lamiaceae & Lavanta & İngiltere & Haziran-Ekim & Süs & Çalı & Herdem yeşil \\
\hline 87 & Lavandula dentata $\mathrm{L}$. & Lamiaceae & Lavanta & Akdeniz ve Atlanta adaları & Haziran-Eylül & Çit & Çalı & Herdem yeşil \\
\hline 88 & Ligustrum vulgare $\mathrm{L}$. & Oleaceae & Adi kurtbağrı & $\begin{array}{l}\text { Avrupa, Kuzey Afrika, } \\
\text { Asya }\end{array}$ & Mayıs-Haziran & Çit & Çalı & Herdem yeşil \\
\hline 89 & Ligustrum japonicum Thunb. & Oleaceae & $\begin{array}{l}\text { Kurtbağrı, } \\
\text { Ligustrum }\end{array}$ & Asya & Mayıs-Ağustos & Çit & $\begin{array}{ll}\text { Çalı veya } \\
\text { Ağaç }\end{array}$ & Herdem yeşil \\
\hline 90 & Liquidambar styraciflua $\mathrm{L}$. & Altingiaceae & $\begin{array}{l}\text { Amber ag̈acı, } \\
\text { günlük ağacı }\end{array}$ & Doğu Amerika, Meksika & - & Süs & Ağaç & Değil \\
\hline 91 & Lonicera periclymenum $\mathrm{L}$. & Caprifoliaceae & Hanımeli & İngiltere & Mayıs-Eylül & Süs & Tirmanici & Herdem yeşil \\
\hline 92 & Lycianthes rantonnei (Carrière) Bitter & Solanaceae & Moryıldız çalısı & Paraguay & Temmuz-Nisan & Süs & Çalı & Herdem yeşil \\
\hline 93 & Magnolia grandiflora $\mathrm{L}$. & Magnoliaceae & Manolya & Güney Amerika & Mayıs-Ağustos & Süs & Ağaç & Değil \\
\hline 94 & Magnolia liliiflora Desr. & Magnoliaceae & Manolya & Çin & Mayıs-Ağustos & Süs & $\begin{array}{ll}\text { Çalı } & \text { veya } \\
\text { Ağaç } & \end{array}$ & Değil \\
\hline 95 & $\begin{array}{l}\text { Malus floribunda Siebold ex Van } \\
\text { Houtte }\end{array}$ & Rosaceae & Süs elmas1 & Japonya & Nisan-Mayis & Süs & Ağaç & Değil \\
\hline 96 & Melia azedarach $\mathrm{L}$. & Meliaceae & Tesbih ağacı & Irak, Japonya, Avustralya & Mayıs-Temmuz & Süs & Ağaç & Değil \\
\hline 97 & Mesembryanthemum cordifolium L.f. & Aizoaceae & Buz çiçeği & Güney Afrika & Nisan-Haziran & Süs & Otsu & Değil \\
\hline 98 & Mespilus germanica $\mathrm{L}$. & Rosaceae & Döngel, Muşmula & Avrupa, Güneybatı Asya & Mayıs-Haziran & Süs & $\begin{array}{ll}\text { Çalı } & \text { veya } \\
\text { Ağaç } & \end{array}$ & Değil \\
\hline 99 & Mirabilis jalapa $\mathrm{L}$. & Nyctaginaceae & $\begin{array}{l}\text { Akşamsefası, } \\
\text { Gecesefası }\end{array}$ & Orta ve Güney Amerika & Haziran-Kasım & Süs & Otsu & Değil \\
\hline 100 & Momordica charantia $\mathrm{L}$. & Cucurbitaceae & Kudret narı & Asya, Afrika & Temmuz-Ağustos & Süs & Tirmanic1 & Değil \\
\hline 101 & Morus alba $\mathrm{L}$. & Moraceae & Dut & Çin, Japonya & - & Süs & Ağaç & Değil \\
\hline 102 & Musa $\times$ paradisiaca $\mathrm{L}$. & Musaceae & Muz & Tropikal Afrika & - & Süs & Ağaç & Herdem yeşil \\
\hline 103 & Nerium oleander $\mathrm{L}$. & Apocynaceae & Zakkum & Kuzey Afrika & Nisan-Eylül & Süs & $\begin{array}{ll}\text { Çalıl } & \text { veya } \\
\text { Ağaç } & \end{array}$ & Herdem yeşil \\
\hline 104 & Oenothera biennis L. & Onagraceae & Ezan çiçeği & Kuzey ve Güney Amerika & Mayıs-Eylül & Süs & Otsu & Değil \\
\hline 105 & Opuntia ficus-indica (L.) Mill. & Cactaceae & Kaynanadili & Meksika & Nisan-Temmuz & Süs & $\begin{array}{l}\text { Otsu } \\
\text { (Sukkulent) }\end{array}$ & Değil \\
\hline 106 & Oxalis articulata Savigny & Oxalidaceae & Ekşiot & Paraguay & Mart-Ekim & Süs & Otsu & Değil \\
\hline 107 & Oxalis pes-caprae $\mathrm{L}$. & Oxalidaceae & Ekşiyonca & Güney Afrika & Kasım-Mayıs & Süs & Otsu & Değil \\
\hline 108 & $\begin{array}{l}\text { Parthenocissus quinquefolia (L.) } \\
\text { Planch. }\end{array}$ & Vitaceae & Amerikan sarmaşı̆̆ı & Kuzey Amerika & - & Çit & Tirmanıcı & Değil \\
\hline 109 & Passiflora caerulea L. & Passifloraceae & Çarkıfelek & Güney Amerika & Haziran-Kasım & Süs & Tirmanıcı & Değil \\
\hline 110 & Paulownia tomentosa Steud. & Paulownaceae & Pavlonya & Doğu Asya & Nisan-Haziran & Süs & Ağaç & Değil \\
\hline 111 & Philadelphus coronarius L. & Hydrangeaceae & Filbahri & Güney Avrupa & Nisan-Haziran & Süs & Çalı & Değil \\
\hline 112 & Phoenix canariensis Chabaud & Arecaceae & Föniks, Hurma & Kanarya Adaları & Mart-Nisan & Süs & Ağaç & Herdem yeşil \\
\hline 113 & Phoenix dactylifera $\mathrm{L}$. & Arecaceae & Hurma & Kuzey Afrika & Mart-Nisan & Süs & Ağaç & Herdem yeşil \\
\hline 114 & Picea pungens Engelm. & Pinaceae & Ladin, Mavi ladin & Amerika & - & Süs & Ağaç & Herdem yeşil \\
\hline
\end{tabular}




\begin{tabular}{|c|c|c|c|c|c|c|c|c|c|}
\hline 115 & Pinus pinaster Aiton & Pinaceae & Sahilçamı, Çam & Akdeniz Bölgesi & - & Süs & Ağaç & & Herdem yeşil \\
\hline 116 & Pinus strobus L. & Pinaceae & Çam, Veymut çamı & Kuzey Amerika & - & Süs & Ağaç & & Herdem yeşil \\
\hline 117 & Pinus wallichiana A.B.Jacks. & Pinaceae & Ağlayan çam & $\begin{array}{l}\text { Afganistan, Pakistan, } \\
\text { Hindistan, Tibet }\end{array}$ & - & Süs & Ağaç & & Herdem yeşil \\
\hline 118 & $\begin{array}{l}\text { Pittosporum tobira } \quad \text { (Thunb.) } \\
\text { W.T.Aiton }\end{array}$ & Pittosporaceae & Taflan & Japonya, Çin & Mayıs-Ağustos & Çit & $\begin{array}{l}\text { Çalı } \\
\text { Ağaç }\end{array}$ & veya & Herdem yeşil \\
\hline 119 & Platycladus orientalis (L.) Franco & Cupressaceae & Doğu Mazısı & Çin, Kore & - & Çit & $\begin{array}{l}\text { Çalı } \\
\text { Ağaç }\end{array}$ & veya & Herdem yeşil \\
\hline 120 & Plumbago auriculata Lam. & Plumbaginaceae & Mavi Yasemin & Güney Afrika & Ocak-Haziran & Süs & Çalı & & Değil \\
\hline 121 & Prunus laurocerasus $\mathrm{L}$ & Rosaceae & Karayemiş, Taflan & Kuzey Amerika & Nisan-Mayıs & Süs & $\begin{array}{l}\text { Çalı } \\
\text { Ağaç }\end{array}$ & veya & Herdem yeşil \\
\hline 122 & Punica granatum $\mathrm{L}$. & Lythraceae & Süs narı & $\begin{array}{l}\text { Akdeniz Bölgesi, Güney } \\
\text { Asya }\end{array}$ & Mayıs-Ağustos & Süs & $\begin{array}{l}\text { Çalı } \\
\text { Ăğaç }\end{array}$ & veya & Değil \\
\hline 123 & Pyracantha coccinea M.Roem. & Rosaceae & Ateş dikeni & Güneydoğu Avrupa & Nisan-Haziran & Süs & Çalı & & Herdem yeşil \\
\hline 124 & Ricinus communis $\mathrm{L}$. & Euphorbiaceae & Hint yağı & Kuzeydoğu Afrika & Haziran-Ekim & Süs & Otsu & & Değil \\
\hline 125 & Robinia pseudoacacia $\mathrm{L}$. & Fabaceae & $\begin{array}{l}\text { Akasya, } \quad \text { Yalancı } \\
\text { Akasya }\end{array}$ & Doğu ve Orta İngiltere & Nisan-Haziran & Süs & Ağaç & & Değil \\
\hline 126 & Rosa banksiae R.Br. & Rosaceae & $\begin{array}{l}\text { Gül, Misket gülü, } \\
\text { Sakız gülü }\end{array}$ & Orta, Batı Çin & Nisan-Mayıs & Süs & Çalı & & Değil \\
\hline 127 & Rosa canina $\mathrm{L}$. & Rosaceae & $\begin{array}{l}\text { İt gülü, kuşburnu, } \\
\text { yaban gülü }\end{array}$ & $\begin{array}{l}\text { Avrupa, Kuzey Afrika, } \\
\text { Batı Asya }\end{array}$ & Mayıs-Temmuz & Süs & Çalı & & Değil \\
\hline 128 & Rosa chinensis Jacq. & Rosaceae & Gül, Yediveren gülü & Güneybatı Çin & Mart-Şubat & Süs & Çalı & & Değil \\
\hline 129 & Rosmarinus officinalis $\mathrm{L}$. & Lamiaceae & Biberiye, Kuşdili & Akdeniz Bölgesi & Haziran-Şubat & Çit & Çalı & & Herdem yeşil \\
\hline 130 & $\begin{array}{l}\text { Russelia equisetiformis Schltdl. \& } \\
\text { Cham. }\end{array}$ & Plantaginaceae & $\begin{array}{l}\text { Mercançalısı, } \\
\text { Ruzelya }\end{array}$ & $\begin{array}{l}\text { Meksika, } \quad \text { Küba, } \\
\text { Kolombiya }\end{array}$ & Haziran-Aralık & süs & Çalı & & Değil \\
\hline 131 & Salix babylonica $\mathrm{L}$. & Salicaceae & Salkım söğüt & Çin & - & süs & Ağaç & & Değil \\
\hline 132 & Salvia microphylla Kunth & Lamiaceae & Süs adaçayı & Kuzeydoğu Meksika & Haziran-Ağustos & Süs & Çalı & & Herdem yeşil \\
\hline 133 & Salvia splendens Sellow ex Schult. & Lamiaceae & Ateş çiçeği & Brezilya & Mayıs-Eylül & Süs & Otsu & & Değil \\
\hline 134 & Salvia fruticosa Mill. & Lamiaceae & Adaçayı, elma çalısı & Türkiye, Yunanistan & Mart-Temmuz & Süs & Çalı & & Değil \\
\hline 135 & Salvia officinalis $\mathrm{L}$. & Lamiaceae & $\begin{array}{l}\text { Adaçayı, } \quad \text { Avrupa } \\
\text { adaçayı }\end{array}$ & $\begin{array}{l}\text { İspanya, Balkanlar, Kuzey } \\
\text { Afrika }\end{array}$ & Haziran-Temmuz & Süs & Çalı & & Değil \\
\hline 136 & Santolina chamaecyparissus $\mathrm{L}$. & Asteraceae & Lavantin, Santolina & Akdeniz Bölgesi & Haziran-Ağustos & Süs & Çalı & & Herdem yeşil \\
\hline 137 & Schinus molle $\mathrm{L}$. & Anacardiaceae & Yalancı Karabiber & Güney Amerika & Nisan-Haziran & Süs & Ağaç & & Herdem yeşil \\
\hline 138 & $\begin{array}{l}\text { Senna corymbosa (Lam.) H.S.Irwin \& } \\
\text { Barneby }\end{array}$ & Fabaceae & Sinameki & $\begin{array}{l}\text { Amerika, } \quad \text { Uruguay, } \\
\text { Arjantin }\end{array}$ & Ağustos-Ekim & Süs & Çalı & & Herdem yeşil \\
\hline 139 & Spiraea $\times$ vanhouttei $($ Briot $)$ Zabel & Rosaceae & Bahçe İspiryası & $\begin{array}{l}\text { Avrupa, Asya, Kuzey } \\
\text { Amerika, Meksika }\end{array}$ & Nisan-Temmuz & Süs & Çalı & & Değil \\
\hline 140 & Styphnolobium japonicum (L.) Schott & Fabaceae & Sofora & Çin & Temmuz-Ağustos & Süs & Ağaç & & Değil \\
\hline 141 & Syringa vulgaris $\mathrm{L}$. & Oleaceae & Leylak & Güneydoğu Avrupa & Mart-Haziran & Süs & $\begin{array}{l}\text { Çalı } \\
\text { Ağaç }\end{array}$ & veya & Değil \\
\hline 142 & Tagetes erecta $\mathrm{L}$. & Asteraceae & Kadife çiçeği & Meksika, Guatemala & Mayıs-Eylül & Süs & Otsu & & Değil \\
\hline 143 & Tilia cordata Mill. & Malvaceae & Ihlamur & Avrupa & Mayı-Haziran & Süs & Ağaç & & Değil \\
\hline
\end{tabular}




\begin{tabular}{|c|c|c|c|c|c|c|c|c|c|}
\hline 144 & Tilia tomentosa Moench & Malvaceae & Ihlamur & & Güneydoğu Avrupa & Mayıs-Haziran & Süs & Ağaç & Değil \\
\hline 145 & $\begin{array}{l}\text { Trachelospermum } \\
\text { (Lindl.) Lem. }\end{array}$ & Apocynaceae & $\begin{array}{l}\text { Kokulu } \\
\text { çiçeği }\end{array}$ & pervane & Doğu ve Güneydoğu Asya & Mayıs-Ağustos & Süs & Tirmanicı & Herdem yeşil \\
\hline 146 & $\begin{array}{l}\text { Trachycarpus fortunei (Hook.) } \\
\text { H.Wendl. }\end{array}$ & Arecaceae & Palmiye & & Japonya & Mayıs-Haziran & Süs & Ağaç & Herdem yeşil \\
\hline 147 & Viburnum opulus $\mathrm{L}$. & Adoxaceae & Kartopu & & Avrupa, Luzey Afrika & Nisan-Ağustos & Çit & Çalı & Değil \\
\hline 148 & Viburnum tinus $\mathrm{L}$. & Adoxaceae & $\begin{array}{l}\text { Defne } \\
\text { Kartopu }\end{array}$ & yapraklı & Akdeniz & Ocak-Haziran & Çit & Çalı & Herdem yeşil \\
\hline 149 & Vitis vinifera $\mathrm{L}$. & Vitaceae & Asma & & Akdeniz & - & Süs & Tirmanıc1 & Değil \\
\hline 150 & $\begin{array}{l}\text { Washingtonia filifera (Linden ex } \\
\text { André) H.Wendl. ex de Bary }\end{array}$ & Arecaceae & $\begin{array}{l}\text { Yelpaze } \\
\text { palmiye }\end{array}$ & yapraklı & Kalifornia & Haziran-Ağustos & Süs & Ağaç & Herdem yeşil \\
\hline 151 & Wisteria sinensis (Sims) Sweet & Fabaceae & Morsalkım & & Çin & Nisan-Eylül & Süs & Tirmanicı & Değil \\
\hline 152 & Yucca filamentosa $\mathrm{L}$. & Asparagaceae & Avize ağacı & & İngiltere & Haziran-Temmuz & Süs & Otsu & Herdem yeşil \\
\hline 153 & Yucca gloriosa $\mathrm{L}$. & Asparagaceae & Avize ağacı & & İngiltere & Mayıs-Kasım & Süs & Otsu & Herdem yeşil \\
\hline 154 & Zantedeschia aethiopica (L.) Spreng. & Araceae & Kala & & Güney Afrika & Nisan-Temmuz & Süs & Otsu & Herdem yeşil \\
\hline 155 & Ziziphus jujuba Mill. & Rhamnaceae & Hünnap & & Çin & Mayıs-Ağustos & süs & Ağaç & Değil \\
\hline
\end{tabular}

